\title{
Measuring the health literacy of the Upper Midwest
}

\author{
Caitlin J. Bakker, MLIS; Jonathan B. Koffel, MSI; Nicole R. Theis-Mahon, MLIS
}

See end of article for authors' affiliations.

\begin{abstract}
Objectives: Health literacy-the ability to obtain, process, and understand basic health information-is a major determinant of an individual's overall health and health care utilization. In this project, the authors examined predictors of health literacy levels, including numeracy and graphic literacy, among an adult population in the Upper Midwest.
\end{abstract}

Methods: The research was conducted at the Minnesota State Fair. Three previously validated scales were used to assess health literacy: Newest Vital Sign, the General Health Numeracy Test, and questions from Galesic and Garcia-Retamero's Graph Literacy Scale. Demographic information-such as age, educational attainment, zip code, and other potential predictors and modifiers-was collected. Multivariate linear regression was conducted to examine the independent effects of educational attainment, race, ethnicity, gender, and rural or urban location on overall health literacy and scores on each of the individual instruments.

Results: A total of 353 Upper Midwest residents completed the survey, with the majority being white, collegeeducated, and from an urban area. Having a graduate or professional degree or being under the age of 21 were associated with increased health literacy scores, while having a high school diploma or some high school education, being Asian American, or being American Indian/Alaska Native were associated with lower health literacy scores.

Conclusion: Advanced health literacy skills, including the ability to calculate and compare information, were problematic even in well-educated populations. Understanding numerical and graphical information was found to be particularly difficult, and more research is needed to understand these deficits and how best to address them.

\section{INTRODUCTION}

Health literacy is the "the degree to which individuals can obtain, process, and understand the basic health information and services they need to make appropriate health decisions" and effectively function in the health care environment [1]. These skills are central to patient-centered care as they inform the ability to engage in the decision-making process, such as deciding when an injury can be treated at home versus when an injury requires a trip to urgent care or understanding how and when an antibiotic should be taken.

Between one-third and one-half of adult Americans are estimated to have low health literacy $[1,2]$, while recent research from the National Center for Education Statistics notes that only 12\% of American adults show the highest level of proficiency on a literacy scale, and only $9 \%$ of adults show the highest level of proficiency when considering numeracy (the ability to make basic calculations and understand relationships) [3]. Lower rates of health literacy have been found among the elderly, minority populations, persons of limited financial means, and those with less than a high school education [2]. Low health literacy is associated with limited understanding of medical information, poor health outcomes, and poor use of health care services, including increased hospitalization and emergency care [4, 5], decreased use of preventative services [6], poor health behaviors $[7,8]$, and inability to take medication as prescribed $[9,10]$.

In addition to the ability to read and interpret textual information, definitions of health literacy 
have expanded to incorporate numeracy and graph literacy (the ability to interpret graphs, charts, and similar graphics). Poor numeracy is associated with inaccurate estimation of risk when considering treatment options and an unwillingness to adhere to medication regimens [11], broadening the potential negative impact of low health literacy. As Furci and O'Donnell note, "our patients are complex beings composed not only of body, but also of mind and spirit. It is this complexity that can make patients a challenge to treat" [12].

Graphs and charts have been proposed as one way to make risk information and other numerical information easier for patients to understand. The underlying idea is that these graphs "facilitat[e] the nonnumeric, holistic, and gist-based translation from quantitative to qualitative meaning" [13]. The effectiveness of graphical representations depends on the patient's ability to accurately interpret the information. Previous research with emergency department patients shows that health literacy and numeracy are poorly correlated [9], but it is unclear whether this holds true for the general population and their specific relationships with graph literacy.

Despite the requirement to include communication skills training in both graduate and undergraduate medical education [14, 15], evidence suggests that clinical faculty may be unprepared to teach and evaluate such skills $[16,17]$. A growing body of literature notes that health literacy and effective communication skills are inconsistently or inadequately addressed in medical education [1822]. Studies have further documented residents' and clinicians' use of ineffective communication strategies [23-26].

With their knowledge of resident and physician instruction methods, information appraisal, and patient education resources, librarians are well positioned to train clinicians in understanding the challenges of health literacy and effectively conveying information. The aim of this study was to examine predictors of and potential correlations between different aspects of health literacy among people living in the Upper Midwest.

\section{METHODS}

\section{Design and participants}

The authors conducted a health literacy survey at the 2015 Minnesota State Fair over 3 days in August and September among adults with a working knowledge of the English language. The Minnesota State Fair is the largest state fair in the United States, with over 1.7 million attendees in 2015 [27]. This setting was chosen because it allowed us to rapidly recruit and reach a population who might not otherwise participate in university- or clinic-based research. Participants received a University of Minnesota backpack, valued at approximately $\$ 2$, as an incentive. The survey took approximately 15 minutes to complete and was offered in paper or on a tablet. This research was approved as exempt by the Institutional Review Board (IRB) at the University of Minnesota.

After reviewing the information and consent sheets, participants were asked to complete the survey and to provide demographic information. We had filed a waiver of documentation of informed consent with the IRB prior to the research, meaning that signed consent forms were not necessary in this research. Our survey was developed from 3 separate instruments to assess 3 different aspects of health literacy. The instrument, which blended components of the 3 previously validated surveys, was found to be internally consistent (Cronbach's alpha coefficient $=0.84$ ).

Health literacy was assessed using the Newest Vital Sign (NVS), a commonly used instrument for assessing health literacy [28]. NVS includes 6 questions related to interpreting nutritional labels and takes approximately 3 minutes to complete. Its internal consistency was established in a previous study with a Cronbach's alpha coefficient of 0.76 [28].

The General Health Numeracy Test (GHNT-6) was used to assess numeracy [29]. This is a 6-item test that takes approximately 5 minutes to complete. The instrument consists of word problems and 1 question related to the interpretation of nutritional labels. The internal consistency of GHNT-6 was previously established with a Kuder-Richardson coefficient of 0.77 [29].

Eight questions from the Graph Literacy Scale (GLS) developed by Galesic and Garcia-Retamero were selected to assess graphic literacy [30]. The GLS was developed to assess an individual's ability to read, compare, and interpret data shown in a chart. The questions were estimated to take approximately 5 minutes to complete, and the complete scale, which has 13 questions, was found 
to be internally consistent in previous research with a Cronbach's alpha of 0.85 [30].

\section{Data analysis}

In addition to the responses to the survey, demographic data on gender, educational attainment, ethnicity, race, and age range were recorded. Five-digit zip codes were recorded and used in conjunction with 2013 urban influence codes (UIC) codes to determine rural and urban locations [31]. Participants who provided zip codes outside of the Upper Midwest region were excluded from our analysis. We defined the Upper Midwest region as North Dakota, Minnesota, Wisconsin, and Iowa. We did not receive responses from individuals from other states in the Upper Midwest, such as South Dakota or Nebraska.

Surveys completed on paper were entered into an electronic system. Double data entry was conducted on 52 of the 256 paper surveys to identify likelihood of discrepancy. No discrepancies were found. Overall health literacy scores were calculated as the percent of the 20 total questions answered correctly.

We conducted multivariate linear regressions to examine the independent effects of educational attainment, race, ethnicity, gender, and rural or urban location on overall health literacy and scores on each of the individual instruments. We dummycoded nonbinary categorical variables (i.e., all but rural versus urban location) as binary variables (e.g., 31-40 years old versus a different age group), which allowed us to compare each group against a reference group. We designated the reference group as women, non-Hispanic, white, $41-50$ years old, with a bachelor's degree, and living in an urban area, as these were the most common respondents in each category. When conducting the analyses, we employed list-wise deletion, only analyzing responses from participants who answered all background and demographics questions.

\section{RESULTS}

Over 3 days, 373 surveys were completed, and 353 ultimately analyzed. Excluded surveys were those completed by individuals located outside of the Upper Midwest region. Respondents were primarily white $(\mathrm{n}=290,82 \%)$, not Hispanic or Latino $(\mathrm{n}=325$, $92 \%)$, and from an urban area $(\mathrm{n}=275,78 \%)$. The majority of respondents $(n=216,61 \%)$ had obtained a bachelor's degree or a graduate or professional degree. Overall participant characteristics and average scores are presented in Table 1. Statistical significance in comparison to the reference group is also noted. Three hundred ten participants responded to all demographics questions and could be included in the regression analyses (Table 2). The fit for each model was generally low $\left(r^{2}\right.$ ranging from $0.17-0.23)$ but significant $(p<0.001$ in all models).

In comparisons with the reference group of 4150 year old white, non-Hispanic, urban-dwelling females with a bachelor's degree, education, race, and age were found to have statistically significant differences when considering overall score. Ethnicity and location were not statistically significant predictors of overall score or scores on any of the individual instruments that constituted the survey. Although not a significant predictor of overall score $(\beta=0.039, p=0.463)$, being male significantly predicted scores on the NVS $(\beta=-0.201, p<0.001)$, GHNT-6 $(\beta=0.143, p=0.010)$, and GLS $(\beta=0.125$, $p=0.021$ ). Being male decreased NVS score by 9.57 percentage points but increased GHNT-6 and GLS scores by 8.35 and 5.30 points, respectively. Age was also a significant predictor, with being $18-20$ years old increasing overall score by 10.62 points $(\beta=0.206$, $p=0.021$ ), increasing GHNT-6 score by 17.37 points $(\beta=0.175, p=0.011)$, and increasing GLS score by 10.31 points $(\beta=0.143, p=0.032)$. Being over the age of 70 significantly decreased GLS score by 16.08 points $(\beta=-0.119, p=0.027)$. Being $21-30$ years old significantly increased GHNT-6 score by 11.03 points $(\beta=0.165, p=0.015)$. Age did not significantly predict NVS score.

Being Asian American $(\beta=-0.172, p=0.002)$ or American Indian/ Alaska Native $(\beta=-0.228, p<0.001)$ decreased overall score by 11.87 and 44.40 points, respectively. Being Asian American significantly decreased NVS $(\beta=-0.176, p=0.002)$ and GLS ( $\beta=-0.176, p=0.002)$ scores by 14.20 and 12.68 points, respectively, although it did not significantly predict GHNT-6 score $(\beta=-1.567, p=0.118)$. Similarly, being American Indian/Alaska Native significantly decreased NVS $(\beta=0.277, p<0.001)$ and GLS $(\beta=-0.217, p<0.001)$ scores by 63.36 and 44.38 points, respectively, but it did not significantly predict GHNT-6 score $(\beta=-1.541, p=0.125)$. Being a member of other racial groups did not significantly predict overall score or scores on individual instruments. 
Table 1 Participant demographics and instrument scores

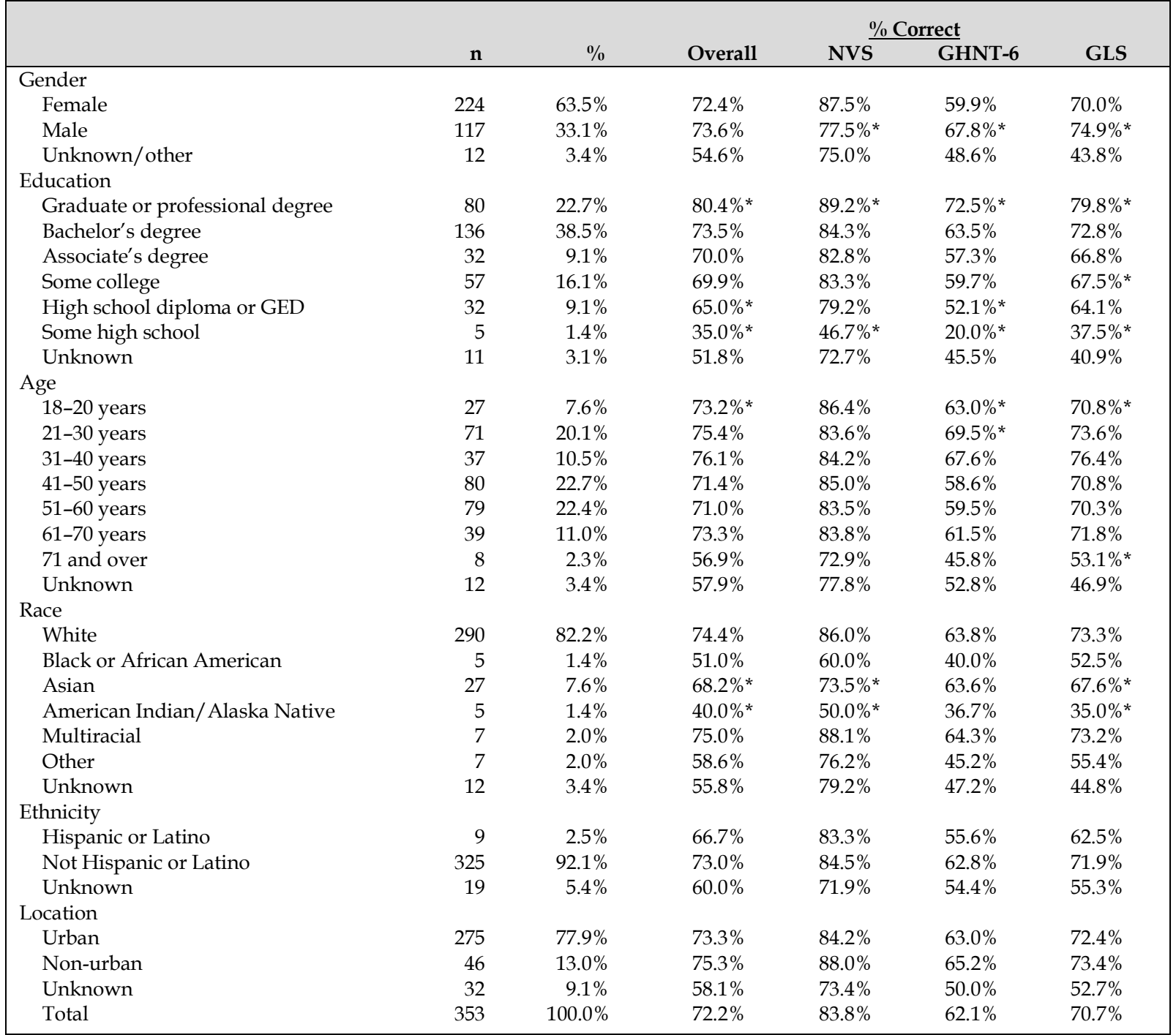

* Statistically significant at $p<0.05$ in comparison to a reference group (women, non-Hispanic, white, 41-50 years old, with a bachelor's degree, and living in an urban area).

Having a graduate or professional degree $(\beta=0.206, p=0.001)$, a high school diploma $(\beta=-1.46$, $p=0.019)$, or less than a high school diploma $(\beta=-$ $0.222, p<0.001$ ) were significant predictors of overall score. Having a graduate or professional degree increased overall score by 9.10 points, while having a high school diploma decreased overall score by 9.39 points, and having less than a high school diploma decreased overall score by 37.56 points. Having an associate's degree $(\beta=-0.001, p=0.984)$ or some college education $(\beta=-0.100, p=0.105)$ was not a significant predictor of overall score. In the analysis of individual instruments in the survey, the upper and lower ends of educational attainment remained significant predictors of GLS, NVS, and GHNT-6 scores. Having a graduate degree significantly predicted NVS $(\beta=0.157, p=0.009,8.13$ point increase), GHNT-6 ( $\beta=0.156, p=0.011,9.92$ point increase), and GLS ( $\beta=0.202, p=0.001,9.37$ point increase) scores. Having less than a high school education also significantly predicted NVS $(\beta=-$ $0.167, p=0.003,33.24$ point decrease), GHNT-6 ( $\beta=-$ $0.213, p<0.001,51.81$ point decrease), and GLS ( $\beta=-$ $0.170, p=0.002,30.21$ point decrease) scores. Having 


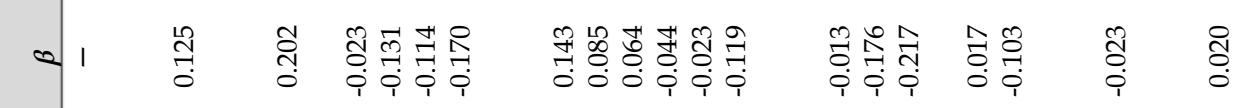

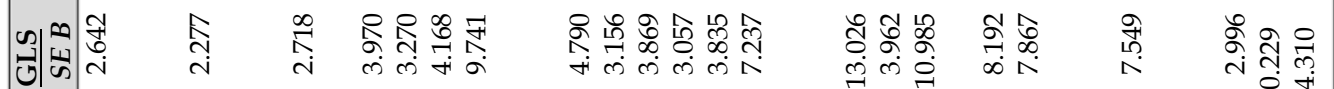

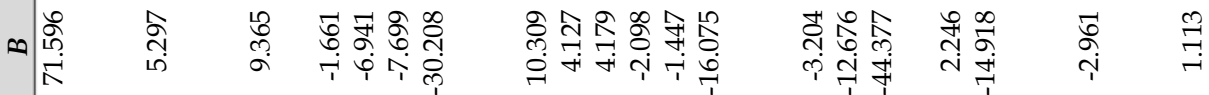

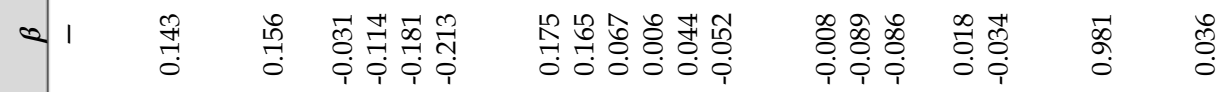

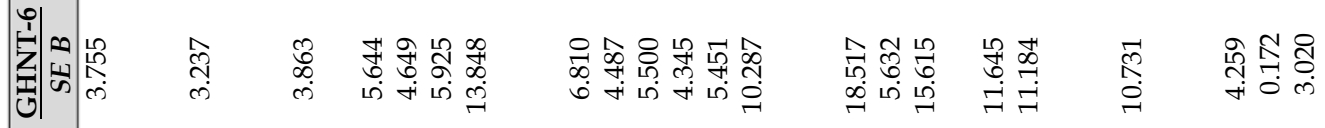

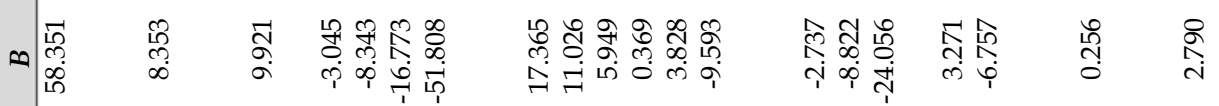

^ 1 矛

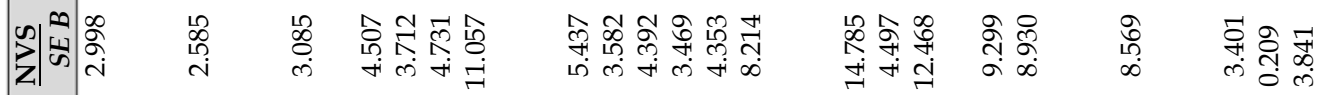

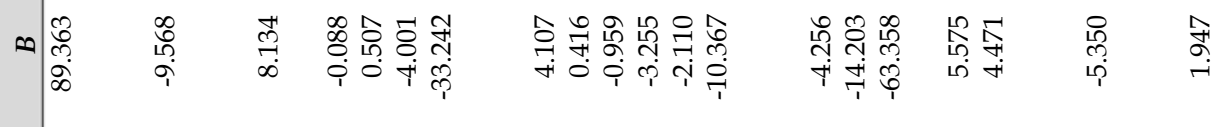

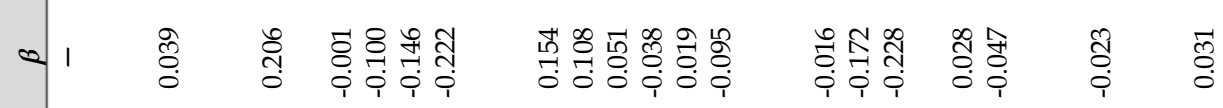

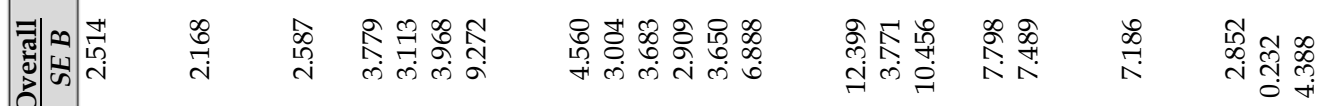

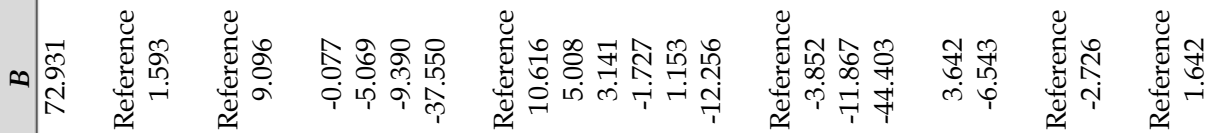

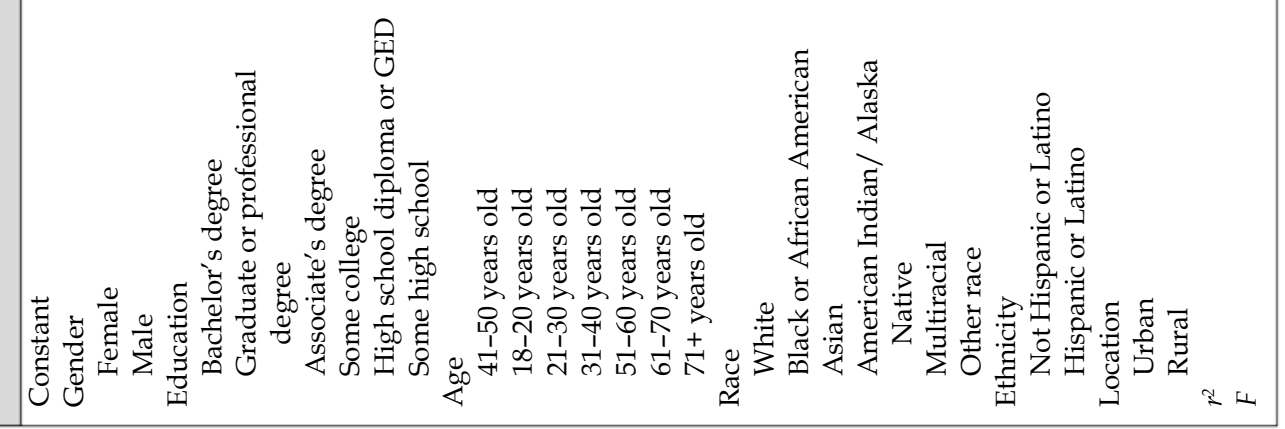


completed some college education significantly predicted GLS score $(\beta=-0.131, p=0.035,6.94$ point decrease), while having attained a high school diploma or GED significantly predicted GHNT-6 score $(\beta=-0.181, p=0.005,16.77$ point decrease). Significant correlations existed between all instruments. GHNT-6 and GLS scores were strongly correlated with overall scores $(r s=0.875$ and 0.833$)$ and strongly correlated with each other $(r=0.617)$. NVS scores were strongly correlated with overall scores $(r=0.654)$ but only weakly or moderately correlated with GHNT- 6 or GLS scores $\left(r_{s}=0.453\right.$ and $0.382)$.

\section{DISCUSSION}

We found that three factors were significant predictors of overall health literacy scores: educational attainment, age, and race. Specifically, having completed a graduate or professional degree or being under the age of twenty-one was associated with higher health literacy, while having a high school education or less than a high school diploma, being Asian American, or being American Indian/Alaska Native was associated with lower health literacy. However, only having completed a graduate or professional degree or having completed less than a high school diploma significantly predicted both the overall score and all individual instrument scores.

Elderly populations have previously been found to have lower levels of health literacy [2]. However, we found that being over the age of seventy was only associated with lower scores in graphic literacy. Being under the age of thirty was a significant predictor of higher numeracy scores, while being under the age of twenty-one was a significant predictor of higher graphic literacy. That younger adults show higher scores on numeracy scales has been previously established, although previous studies have reported that the elderly "demonstrate significantly lower numeracy" [32], which was not supported by our results. The assessment of health literacy levels among older adults has proved somewhat controversial, as notably different levels of adequacy and inadequacy are found when using different measures [33].

Being Asian American or American Indian/Alaska Native was a significant predictor of lower overall health literacy score as well as all scores on all individual instruments except the numeracy scale. Although our small sample sizes limit the conclusions that can be drawn, these significant associations should not be dismissed entirely, as these 2 groups are particularly important in the Upper Midwest. Between 2010 and 2015, Asian Americans were the fastest growing racial minority in these 4 states, increasing from 410,884 to 511,815 [34]. While the American Indian and Alaska Native population has not grown as dramatically, it remains substantial in these regions, with populations of indigenous people being higher in Minnesota and North Dakota than the national average [34]. That only 2 of the minority groups were significant predictors of low health literacy is somewhat surprising. In a systematic review of 85 studies, it was found that " $[\mathrm{t}]$ he rate of black subjects was significantly associated with the rate of low literacy" [35], although it was noted that several confounding factors, such as educational attainment, might have influenced those results.

Broad categorizations are limited in that they do not consider factors unique to distinct ethnic groups and, particularly in the case of Asian Americans, may be overly simplistic. As Kim and Keefe note, there are between twenty-seven and thirty-two Asian American groups in the United States, each of which may have its own economic, cultural, linguistic, social, and political context impacting health [36]. This project did not aim to provide the granularity necessary to examine predictors of health literacy and behaviors among the diverse ethnic groups within these broader categories, as there was already a relatively extensive body of literature available on these topics [36-39]. However, that membership in these substantial minority groups was found to be a significant predictor of poor health literacy should be considered in developing and implementing context-specific educational interventions. This finding may indicate the importance of considering cultural competence and its relationship to health literacy training. Further research is needed, however, to validate and examine the potential effect of race on health literacy.

While our findings that low health literacy was associated with lower levels of education supported the connection between academic achievement and health behaviors [35, 40], higher levels of educational attainment did not necessarily result in consistently high scores across all aspects of health literacy. At every level of educational attainment, 
the same pattern was noted: scores were highest on the NVS and lowest on the GHNT-6. In the case of individuals with graduate or professional degrees, the average NVS score was 89.2 , but the average GHNT-6 score was only 72.5. Consistent with previous research, this result suggests that completing basic numeracy questions poses a challenge and that numeracy skills cannot be assumed by level of education [41]. Although the mean numeracy score among graduate degree holders was 10 points higher than the overall average of $62.1,30 \%(n=24)$ of respondents with graduate degrees scored $50 \%$ or less on this scale. When examining responses to individual questions in the survey, questions that required comprehension of information, such as reading a number off a graph, appeared to be easier for respondents than questions that required calculations or inference. Given that participants had access to calculators, pens, and paper and were given unlimited time, one can also imagine the potential challenge of receiving and understanding such information verbally and in a stressful situation, such as when being seen in a doctor's office or when making difficult decisions regarding treatment options.

Our findings echo Mayer's Multimedia Learning Principle that "people learn better from words and pictures than from words alone" [42]. Strategies that incorporate multiple methods of communicating information have been shown to positively impact patient outcomes. One study showed that a pictogram-based intervention augmented with demonstration and teach-back methods reduced caregiver dosing errors [43]. A disease-management intervention that incorporates plain language, teachback, and visual aids is associated with a greater likelihood of achieving prescribed health outcomes [44]. Previous research had indicated that health literacy interventions for medical students including teaching plain language skills, teach-back techniques, and the use of universal precautions lead to significant improvement in self-reported knowledge and planned behaviors [45]. Medical educators can assist residents and clinicians with using these strategies and developing these skills to effectively communicate health information to patients and caregivers. Brown and Bylund's "Breaking Bad News" module, in their communication skills training workshop, outlined strategies for providing understandable information to patients, including avoiding jargon, using a variety of methods for conveying information, and offering written information [46]. Medical educators have also addressed these skills in a variety of formats, including role-playing [47], interactive workshops [48], and problem-based learning [49].

One approach to increase health literacy is to utilize and involve librarians in educating residents and physicians, particularly through community and faculty partnerships $[50,51]$. For example, at the University of Minnesota, library integration into a required third-year course for all medical students has provided an opportunity to discuss the importance of plain language and health literacy. This session incorporates a graded component in which the students must translate findings from scholarly articles into patient education resources. Librarians at the University of Manitoba offer similar instruction to first-year family medicine residents during a half-day session that incorporates active learning elements, including administering health literacy screening tools such as NVS for clinical use [52]. Librarians at the University of Utah have been actively engaged in their university-wide Health Literacy Interest Group since 2006 and have hosted workshops and lectures on this topic.

Recently, the libraries at University of Utah were involved in Healthi4U, a competition that encouraged students to create videos focused on health care topics in a variety of languages. The winning videos are now being broadcast on the patient education channel at University of Utah Health Care and through the Utah Educational Network's television station [53]. However, despite these successful partnerships, literature on librarianled educational interventions remains limited.

Consideration of all aspects of health literacy is imperative for clinicians as they engage patients in the decision-making process. More advanced skills, including the abilities to calculate and to compare information, remain problematic even for welleducated populations. Although there are ongoing attempts by medical educators to develop these skills in medical students, residents, and clinicians, increased librarian involvement could provide a beneficial perspective.

\section{Study limitations}

This study employed non-probability sampling, and therefore, its sample is not representative of all 
individuals in the Upper Midwest. This is most notable when considering educational attainment. While $32.5 \%$ of American adults have a bachelor's degree or higher [34], $61 \%$ of our study respondents held these same credentials. While this limits the generalizability of our findings, this overrepresentation is not unexpected in a selfselecting group, as individuals with higher educational attainment are more likely to participate in surveys [54]. Also, standard values for adequate health literacy have not been established for the GHNT-6 or GLS, which instead rely on percent correct or median split. Further research that includes systematic or stratified samples and standard values for numeracy and graphic literacy is necessary to establish a baseline of health literacy in the general population.

\section{ACKNOWLEDGMENTS}

The authors thank Janice Jaguszewski, Lisa McGuire, Katherine Chew, and Franklin Sayre for their support of and assistance with this project.

\section{REFERENCES}

1. Nielsen-Bohlman L, Panzer AM, Kindig DA, eds., Institute of Medicine. Health literacy: a prescription to end confusion. Washington, DC: National Academies Press; 2004.

2. Kutner M, Greenberg E, Jin Y, Paulsen C. The health literacy of America's adults: results from the 2003 National Assessment of Adult Literacy (NCES 2006-483) [Internet]. Washington, DC: National Center for Education Statistics; Sep 2006 [cited 14 Mar 2016]. <http:// files.eric.ed.gov/fulltext/ED493284.pdf>.

3. Berkman ND, Sheridan SL, Donahue KE, Halpern DJ, Crotty K. Low health literacy and health outcomes: an updated systematic review. Ann Intern Med. 2011 Jul 19;155(2):97107. DOI: http:/ / dx.doi.org/10.7326/0003-4819-155-2201107190-00005.

4. Goodman M, Finnegan R, Mohadjer L, Krenzke T, Hogan J, Owen E, Provasnik S. Literacy, numeracy, and problem solving in technology-rich environments among U.S. adults: results from the Program for the International Assessment of Adult Competencies 2012 (NCES 2014-008) [Internet]. Washington, DC: National Center for Education Statistics; Oct 2013 [cited 10 Aug 2016]. <https://nces.ed.gov/pubs2014/2014008.pdf>.

5. Wu JR, Holmes GM, DeWalt DA, Macabasco-O'Connell A, Bibbins-Domingo K, Ruo B, Baker DW, Schillinger D, Weinberger M, Broucksou KA, Erman B, Jones CD, Cene $\mathrm{CW}$, Pignone M. Low literacy is associated with increased risk of hospitalization and death among individuals with heart failure. J Gen Intern Med. 2013 Sep;28(9):1174-80. DOI: http://dx.doi.org/10.1007/s11606-013-2394-4.
6. Lindau ST, Tomori C, Lyons T, Langseth L, Bennett CL, Garcia P. The association of health literacy with cervical cancer prevention knowledge and health behaviors in a multiethnic cohort of women. Am J Obstet Gynecol. 2002 May;186(5):938-43. DOI: http://dx.doi.org/10.1067/mob.2002.122091.

7. Aboumatar HJ, Carson KA, Beach MC, Roter DL, Cooper LA. The impact of health literacy on desire for participation in healthcare, medical visit communication, and patient reported outcomes among patients with hypertension. J Gen Intern Med. 2013 Nov;28(11):1469-76. DOI: http:/ / dx.doi.org/10.1007/s11606-013-2466-5.

8. Stewart DW, Cano MA, Correa-Fernández V, Spears CA, Li Y, Waters AJ, Wetter DW, Vidrine JI. Lower health literacy predicts smoking relapse among racially/ethnically diverse smokers with low socioeconomic status. BMC Public Health. 2014 Jan;14(1):716. DOI: http://dx.doi.org/10.1186/14712458-14-716.

9. Griffey RT, Melson AT, Lin MJ, Carpenter CR, Goodman MS, Kaphingst K. Does numeracy correlate with measures of health literacy in the emergency department? Acad Emerg Med. 2014 Feb;21(2):147-53. DOI: http://dx.doi.org/10.1111/acem.12310.

10. Bennin F, Rother HA. “But it's just paracetamol": caregivers' ability to administer over-the-counter painkillers to children with the information provided. Patient Educ Couns. 2015 Mar;98(3):331-7. DOI: http://dx.doi.org/10.1016/j.pec.2014.11.025.

11. Peters E, Hart PS, Tusler M, Fraenkel L. Numbers matter to informed patient choices: a randomized design across age and numeracy levels. Med Decis Making. 2014 May;34(4):430-42. DOI: http://dx.doi.org/10.1177/0272989X13511705.

12. Furci DR, O'Donnell JA. Word pictures as a teaching tool for residents and medical students. Osteopath Fam Physician. 2010 Mar;2(2):53-4. DOI: http://dx.doi.org/10.1016/j.osfp.2009.09.002.

13. Keller C, Kreuzmair C. Numeric and graphic risk information processing of high and low numerates in the intuitive and deliberative decision modes: an eye-tracker study. Judgm Decis. 2014 Sep;9(5):420-32.

14. Accreditation Council for Graduate Medical Education (ACGME). Common program requirements [Internet]. Chicago, IL: The Council; 2007 [rev. 28 Sep 2014; cited Mar 14 2016]. <http:// www.acgme.org/What-WeDo/Accreditation/Common-Program-Requirements>.

15. Duffy FD, Gordon GH, Whelan G, Cole-Kelly K, Frankel R, Buffone N, Lofton S, Wallace M, Godoe L, Langdon L. Assessing competence in communication and interpersonal skills: the Kalamazoo II report. Acad Med. 2004 Jun;79(6):495-507.

16. Mueller PS, Barrier PA, Call TG, Duncan AK, Hurley DL, Multari A, Rabatin JT, Li JTC. Views of new internal medicine faculty of their preparedness and competence in physician-patient communication. BMC Med Educ. 2006;6:article 30. DOI: http:/ / dx.doi.org/10.1186/14726920-6-30. 
DOI: dx.doi.org/10.5195/jmla.2017.105

17. Buyck D, Lang F. Teaching medical communication skills: a call for greater uniformity. Fam Med. 2002 May;34(5):33743

18. Ali NK. Are we training residents to communicate with low health literacy patients? J Community Hosp Intern Med Perspect. 2012;2(4). DOI: http:/ / dx.doi.org/10.3402/ichimp.v2i4.19238.

19. Coleman CA, Appy S. Health literacy teaching in US medical schools, 2010. Fam Med. 2012 Jul-Aug;44(7):504-7.

20. Karsenty C, Landau M, Ferguson R. Assessment of medical resident's attention to the health literacy level of newly admitted patients. J Community Hosp Intern Med Perspect. 2013 Dec;3(3-4). DOI: http://dx.doi.org/10.3402/jchimp.v3i3-4.23071.

21. Powell CK, Kripalani S. Brief report: resident recognition of low literacy as a risk factor in hospital readmission. J Gen Intern Med. 2005 Nov;20(11):1042-4.

22. Ali NK, Ferguson RP, Mitha S, Hanlon A. Do medical trainees feel confident communicating with low health literacy patients? J Community Hosp Intern Med Perspect. 2014 Apr;4(2). DOI: http:/ / dx.doi.org/10.3402/jchimp.v4.22893.

23. Deuster L, Christopher S, Donovan J, Farrell M. A method to quantify residents' jargon use during counseling of standardized patients about cancer screening. J Gen Intern Med. 2008 Dec;23(12):1947-52. DOI: http://dx.doi.org/10.1007/s11606-008-0729-3.

24. McCarthy DM, Waite KR, Curtis LM, Engel KG, Baker DW, Wolf MS. What did the doctor say? health literacy and recall of medical instructions. Med Care. 2012 Apr;50(4):277-82. DOI: http:/ / dx.doi.org/10.1097/MLR.0b013e318241e8e1.

25. Howard T, Jacobson KL, Kripalani S. Doctor talk: physicians' use of clear verbal communication. J Health Commun. 2013 Aug;18(8):991-1001. DOI: http://dx.doi.org/10.1080/10810730.2012.757398.

26. Farrell MH, Kuruvilla P, Eskra KL, Christopher SA, Brienza RS. A method to quantify and compare clinicians' assessments of patient understanding during counseling of standardized patients. Patient Educ Couns. 2009 Oct;77(1):128-35. DOI: http:// dx.doi.org/10.1016/j.pec.2009.03.013.

27. Minnesota State Fair. 2013-2015 detailed daily attendance [Internet]. The Fair [cited 11 Aug 2016]. $<$ http://www.mnstatefair.org/general_info/attendance.ht $\underline{\mathrm{ml}}>$.

28. Weiss BD, Mays MZ, Martz W, Castro KM, DeWalt DA, Pignone MP, Mockbee J, Hale FA. Quick assessment of literacy in primary care: the Newest Vital Sign. Ann Fam Med. 2005 Nov 1;3(6):514-22. DOI: http://dx.doi.org/10.1370/afm.405.

29. Osborn CY, Wallston KA, Shpigel A, Cavanaugh K, Kripalani S, Rothman RL. Development and validation of the General Health Numeracy Test (GHNT). Patient Educ Couns. 2013 Jun;91(3):350-6. DOI: http://dx.doi.org/10.1016/i.pec.2013.01.001.

30. Galesic M, Garcia-Retamero R. Graph literacy: a crosscultural comparison. Med Decis Making. 2011
May/Jun;31(3):444-57. DOI:

http://dx.doi.org/10.1177/0272989X10373805.

31. US Department of Agriculture Economic Research Service. Urban influence codes [Internet]. The Department; 8 Jul 2013 [cited 28 Jan 2016]. <http://www.ers.usda.gov/dataproducts/urban-influence-codes.aspx $>$.

32. Chen Y, Wang J, Kirk RM, Pethtel OL, Kiefner AE. Age differences in adaptive decision making: the role of numeracy. Educ Gerontol. 2014 Nov; 40(11):825-33. DOI: http:/ / dx.doi.org/10.1080/03601277.2014.900263.

33. Levy H, Janke AT, Langa KM. Health literacy and the digital divide among older Americans. J Gen Intern Med. 2015 Mar;30(3):284-9. DOI: http:// dx.doi.org/10.1007/s11606014-3069-5.

34. US Census Bureau. PEPASR5H: annual estimates of the resident population by sex, age, race alone or in combination, and Hispanic origin for the United States and states: April 1, 2010 to July 1, 2015 [Internet]. The Bureau; Jun 2016 [cited 10 Aug 2016]. $<$ http:// factfinder.census.gov>

35. Paasche-Orlow MK, Parker RM, Gazmararian JA, NielsenBohlman LT, Rudd RR. The prevalence of limited health literacy. J Gen Intern Med. 2005 Feb;20(2):175-84. DOI: http://dx.doi.org/10.1111/j.1525-1497.2005.40245.x.

36. Kim WS, Keefe RH. Barriers to healthcare among Asian Americans. Soc Work Public Health. 2010 May;25(3):286-95. DOI: http:/ / dx.doi.org/10.1080/19371910903240704.

37. Nakagami K, Yamauchi T, Noguchi H, Maeda T, Nakagami $\mathrm{T}$. Development and validation of a new instrument for testing functional health literacy in Japanese adults. Nurs Health Sci. 2014 Jun;16(2):201-8. DOI: http://dx.doi.org/10.1111/nhs.12087.

38. Lee HY, Lytle K, Yang PN, Lum T. Mental health literacy in Hmong and Cambodian elderly refugees: a barrier to understanding, recognizing, and responding to depression. Int J Aging Hum Dev. 2010 Dec;71(4):323-44. DOI: http://dx.doi.org/10.2190/AG.71.4.d.

39. Lee HY, Rhee TG, Kim NK, Ahluwalia JS. Health literacy as a social determinant of health in Asian American immigrants: findings from a population-based survey in California. J Gen Intern Med. 2015 Aug;30(8):1118-24. DOI: http://dx.doi.org/10.1007/s11606-015-3217-6.

40. Bradley BJ, Greene AC. Do health and education agencies in the United States share responsibility for academic achievement and health? a review of 25 years of evidence about the relationship of adolescents' academic achievement and health behaviors. J Adolesc Heal. 2013 May;52(5):52332. DOI:

http://dx.doi.org/10.1016/j.jadohealth.2013.01.008.

41. Lipkus IM, Samsa G, Rimer BK. General performance on a numeracy scale among highly educated samples. Med Decis Mak. 2001 Feb;21(1):37-44. DOI: http:// dx.doi.org/10.1177/0272989X0102100105.

42. Mayer RE. Multimedia learning. 2nd ed. New York, NY: Cambridge University Press; 2009.

43. Yin HS, Dreyer BP, van Schaick L, Foltin GL, Dinglas C, Mendelsohn AL. Randomized controlled trial of a 
pictogram-based intervention to reduce liquid medication dosing errors and improve adherence among caregivers of young children. Arch Pediatr Adolesc Med. 2008 Sep;162(9):814-22. DOI: http://dx.doi.org/10.1001/archpedi.162.9.814.

44. Rothman RL, DeWalt DA, Malone R, Bryant B, Shintani A, Crigler B, Weinberger M, Pignone M. Influence of patient literacy on the effectiveness of a primary care-based diabetes disease management program. JAMA. 2004 Oct 13;292(14):1711-6. DOI: http://dx.doi.org/10.1001/jama.292.14.1711.

45. Coleman CA, Peterson-Perry S, Bumsted T. Long-term effects of a health literacy curriculum for medical students. Fam Med. 2016 Jan;48(1):49-53.

46. Brown RF, Bylund CL. Communication skills training: describing a new conceptual model. Acad Med. 2008 Jan;83(1):37-44.

47. Chandawarkar RY, Ruscher K, Krajewski A, Garg M, Pfeiffer C, Singh R, Longo WE, Kozol RA, Lesnikoski B, Nadkarni P. Pretraining and posttraining assessment of residents' performance in the fourth Accreditation Council for Graduate Medical Education competency: patient communication skills. Arch Surg. 2011;146(8):916-21. DOI: http:/ / dx.doi.org/10.1001/archsurg.2011.167.

48. Zoberi K, Everard K, Deckert J, Frankenstein L. Health literacy for clerkship students. MedEdPORTAL Publications [Internet]. 2008;4:732 [cited 14 Mar 2016]. <https://www.mededportal.org/publication/732>.

49. Lypson M, Perlman R, Stalburg C, Johnston C, Lash R, Ross $P$. What patients bring to the medical encounter? dealing with the whole patient. MedEdPORTAL Publications [Internet]. 2010;6:8068 [cited 14 Mar 2016]. <https://www.mededportal.org/publication/8068>.

50. Hess J, Whelan JS. Making health literacy real: adult literacy and medical students teach each other. J Med Libr Assoc. 2009 Jul;97(3):221-4. DOI: http:/ / dx.doi.org/10.3163/15365050.97.3.012.
51. Aspinall EE, Beschnett A, Ellwood AF. Health literacy for older adults: using evidence to build a model educational program. Med Ref Serv Q. 2012 Jul;31(3):302-14. DOI: http://dx.doi.org/10.1080/02763869.2012.698174.

52. Swajcer A, Macdonald K, Kvern B. Health literacy training for family medicine residents. J Can Health Libr Assoc. 2014 Dec;35(3):128-32. DOI: http:// dx.doi.org/10.5596/c14-033.

53. Shipman JP, Lake E, Weber AI. Improving health literacy: health sciences library case studies. Ref Serv Rev. 2016;44(2):206-14. DOI: http:// dx.doi.org/10.1108/RSR-032016-0022.

54. Singer E, Van Hoewyk J, Maher MP. Experiments with incentives in telephone surveys. Public Opin Q. 2000 Aug;64(2):171-88. DOI: http:// dx.doi.org/10.1086/317761.

\section{AUTHORS' AFFILIATIONS}

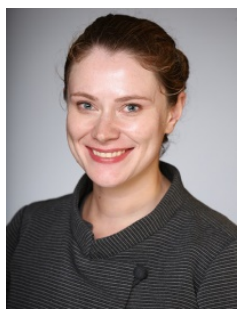

Caitlin J. Bakker, MLIS,

cjbakker@umn.edu, Assistant Librarian, Health Sciences Libraries, University of Minnesota-Twin Cities, 505 Essex Street SE, Minneapolis, MN, 55455

Jonathan B. Koffel, MSI,

jbkoffel@umn.edu, Associate Librarian, Health Sciences Libraries, University of Minnesota-Twin Cities, 505 Essex Street SE, Minneapolis, MN, 55455

Nicole R. Theis-Mahon, MLIS, theis025@umn.edu, Assistant Librarian, Health Sciences Libraries, University of MinnesotaTwin Cities, 505 Essex Street SE, Minneapolis, MN, 55455

Received May 2016; accepted August 2016

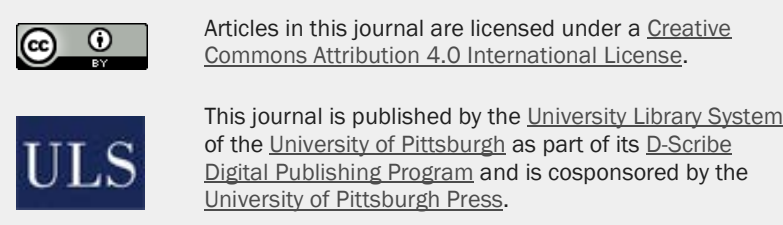

ISSN 1558-9439 (Online) 